\title{
Synthesis and Structural Characterization of $\mathrm{Al}_{2} \mathrm{O}_{3}$-Coated $\mathrm{MoS}_{2}$ Spheres for Photocatalysis Applications
}

\author{
S. V. Prabhakar Vattikuti and Chan Byon \\ School of Mechanical Engineering, Yeungnam University, Gyeongsan 712-749, Republic of Korea \\ Correspondence should be addressed to Chan Byon; cbyon@ynu.ac.kr
}

Received 8 April 2015; Revised 21 May 2015; Accepted 27 May 2015

Academic Editor: Junyou Yang

Copyright ( 2015 S. V. P. Vattikuti and C. Byon. This is an open access article distributed under the Creative Commons Attribution License, which permits unrestricted use, distribution, and reproduction in any medium, provided the original work is properly cited.

\begin{abstract}
This paper reports the synthesis of novel monodisperse $\mathrm{Al}_{2} \mathrm{O}_{3}$-coated molybdenum disulfide nanospheres (i.e., core-shell structures) using a one-step facile hydrothermal method. XPS analysis confirmed the purity and stable structure of the $\mathrm{Al}_{2} \mathrm{O}_{3}$ coated $\mathrm{MoS}_{2}$ nanospheres. A possible growth mechanism of the core-shell structure is also reported, along with their influence on the photodegradation process of rhodamine $\mathrm{B}(\mathrm{RhB})$. The $\mathrm{Al}_{2} \mathrm{O}_{3}$-coated $\mathrm{MoS}_{2}$ nanospheres demonstrate good photocatalytic activity and chemical stability compared to $\mathrm{MoS}_{2}$ spheres. TG-DTA analysis provided insight into the decomposition process of the precursor solution and the stability of the nanoparticles. The enhanced photocatalytic activity makes the $\mathrm{Al}_{2} \mathrm{O}_{3}$ - $\mathrm{Coated}_{\mathrm{MoS}}$ nanospheres a promising candidate as a photocatalyst that could be used in place of traditional $\mathrm{Al}_{2} \mathrm{O}_{3} / \mathrm{MoS}_{2}$ photocatalyst for the removal of pollutants from waste water.
\end{abstract}

\section{Introduction}

Molybdenum disulfide $\left(\mathrm{MoS}_{2}\right)$ is one of the important transition metal dichalcogenides (TMDs) with indirect band gap $(1.23 \mathrm{eV})$ semiconductor characteristics [1]. Because of their outstanding properties like mechanical-to-electrochemical capabilities, $\mathrm{MoS}_{2}$ is used in wide spectrum of applications in catalytic support materials [2,3], solar cells [4], batteries [5], solid lubricants [6], and gas sensors [7]. These unique properties have attracted many researchers to design new synthesis approaches for uniform and well-controlled $\mathrm{MoS}_{2}$ nanostructures. Synthesis methods include chemical vapor deposition [8], wetness impregnation method [9], hydrothermal methods [10], and solid state reaction [11]. These techniques have been used to prepare various morphologies of $\mathrm{MoS}_{2}$, like fullerene-like (IF) structures, nanoflowers, nanorods, nanosheets, nanoplates, and nanospheres.

In a recent report, Wang et al. demonstrated that carbondecorated $\mathrm{MoS}_{2}$ nanospheres have better cycling performance with good capacity as a Na-iron battery anode [12]. $\mathrm{MoS}_{2}$ is clearly one of the most significantly and broadly used TMDs for transistors due to its favorable band gap compared to graphene. In addition, $\mathrm{MoS}_{2}$ is also a suitable candidate for photocatalytic materials. $\mathrm{MoS}_{2}$ is an indirect narrow-band-gap semiconductor with good stability against photocorrosion in solution [13]. General issues with semiconductor catalysts in the conversion of solar energy to hydrogen are poor charge transport ability, slow kinetics for evolution reactions, poor stability, and the hydrophobic nature of the catalyst $[14,15]$. On the other hand, individual $\mathrm{MoS}_{2}$ catalyst has lower charge separation due to its poor crystallinity.

Despite previous efforts, there has been no material system that can simultaneously satisfy all the criteria for costeffective photoelectrochemical hydrogen production, and new materials with new properties are needed. To overcome these problems, core-shell structures of $\mathrm{MoS}_{2}$ coupled with another material with different activity are promising. Such structures could enable charge separation by gathering electrons and holes. The major parameters for the selection of shell materials are band alignment and small lattice mismatch between the core and shell materials [16]. There are very few studies that have focused on preparing $\mathrm{MoS}_{2}$ nanosphere structures. Wu et al. [17] synthesized $\mathrm{MoS}_{2}$ microspheres (with diameter up to $2 \mu \mathrm{m}$ ) using a solvothermal method 


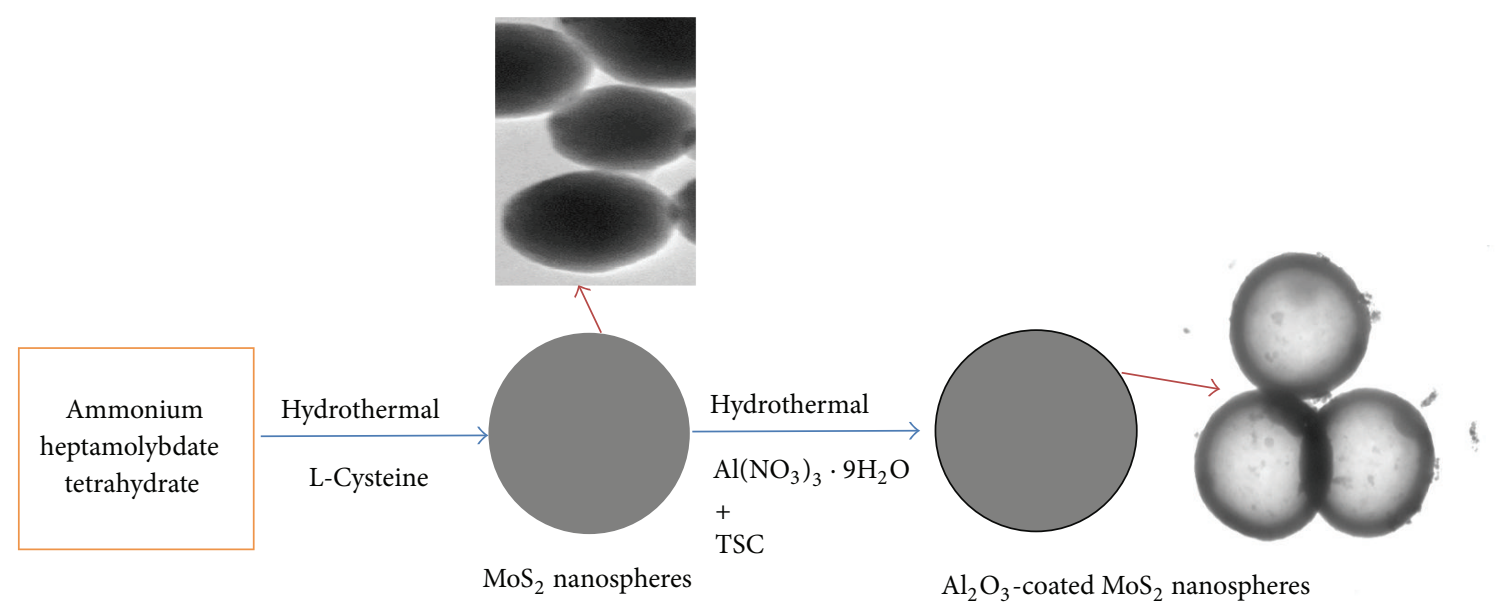

FIGURE 1: Schematic illustration of the methodology for the formation of $\mathrm{Al}_{2} \mathrm{O}_{3}$-coated $\mathrm{MoS}_{2}$ nanospheres.

with the addition of SUDEI. Wu et al. [18] prepared $\mathrm{MoS}_{2}$ nanospheres (with average diameter of $100 \mathrm{~nm}$ ) using $\mathrm{HCl}$ as a surfactant. Park et al. [19] synthesized $\mathrm{MoS}_{2}$ nanospheres with high capacity and cycle stability for lithium ion batteries using L-cysteine in a surfactant-assisted solvothermal route.

Common ways to synthesize core-shell structures are decorating the core particles with a surface coating [5] or shell formation using surface modification processes [20]. In this study, we report the influence of $\mathrm{Al}_{2} \mathrm{O}_{3}$ as a shell material on the photocatalytic activity of $\mathrm{MoS}_{2}$ nanosphere coreshell structures under UV light irradiation. We studied the variations of the activity and selectivity in the degradation of rhodamine $\mathrm{B}(\mathrm{RhB})$ using $\mathrm{Al}_{2} \mathrm{O}_{3}$-coated $\mathrm{MoS}_{2}$ nanospheres as a catalyst.

\section{Experimental Procedure}

A schematic illustration of the methodology for the formation of $\mathrm{Al}_{2} \mathrm{O}_{3}$-coated $\mathrm{MoS}_{2}$ nanospheres is shown in Figure 1. For the synthesis, $0.3 \mathrm{~g}$ of ammonium heptamolybdate tetrahydrate and $0.17 \mathrm{~g}$ of L-cysteine were dissolved in $30 \mathrm{~mL}$ of deionized water. This solution was stirred vigorously for $1 \mathrm{~h}$ at $80^{\circ} \mathrm{C}$. The suspension was continuously stirred and refluxed near $\mathrm{pH} 1$. Then, $1.2 \mathrm{mmol}$ of $\mathrm{Al}\left(\mathrm{NO}_{3}\right)_{3} \cdot 9 \mathrm{H}_{2} \mathrm{O}$ and $0.3 \mathrm{mmol}$ of trisodium citrate dehydrate (TSC) were added to the stirred solution and again stirred for $30 \mathrm{~min}$ at $80^{\circ} \mathrm{C}$. Then, the solution was transferred to a Teflon-lined autoclave and heated at $230^{\circ} \mathrm{C}$ for $24 \mathrm{~h}$. Finally, the resulting precipitates were collected by centrifugation and then the precipitates were washed three times with acetone and water. The obtained precipitates were dried at $250^{\circ} \mathrm{C}$ for $6 \mathrm{~h}$ and sintering at $450^{\circ} \mathrm{C}$ for $2 \mathrm{~h}$.

The structural properties of the obtained precipitates were characterized by powder X-ray diffraction (XRD) with a Shimadzu Labx XRD 6100 using $\mathrm{Cu}-\mathrm{K} \alpha$ radiation $(\lambda$ $=0.14056 \mathrm{~nm}$ ). The scan range was $10-80^{\circ}$, and the scan speed was $3 \mathrm{deg} / \mathrm{min}$. The nanoparticles were analyzed with a transmission electron microscope (TEM, Hitachi H-7000) at $100 \mathrm{kV}$ and a high-resolution TEM (HRTEM, Tecnai G ${ }^{2}$ F 20

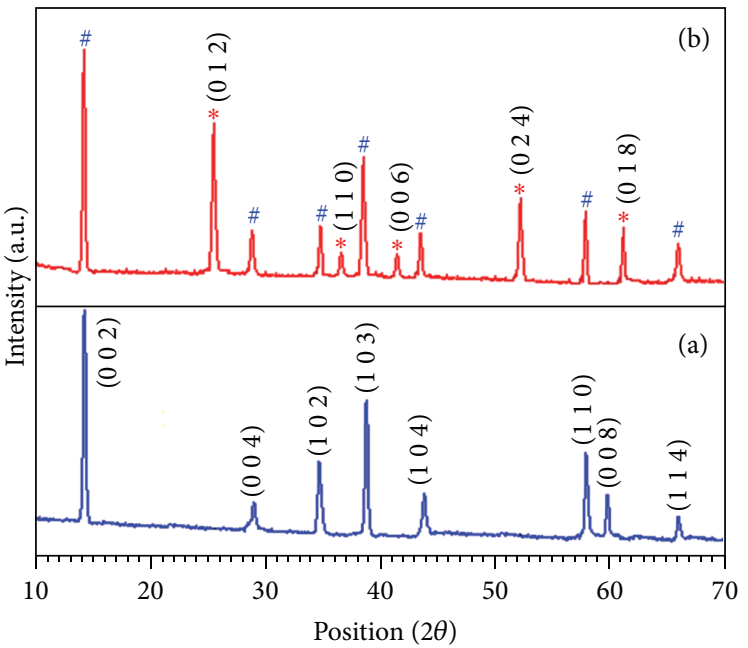

$$
\begin{aligned}
& \text { \# } \mathrm{MoS}_{2} \\
& \text { * } \mathrm{Al}_{2} \mathrm{O}_{3}
\end{aligned}
$$

FIGURE 2: XRD pattern of $\mathrm{MoS}_{2}$ nanospheres (curve (a)) and $\mathrm{Al}_{2} \mathrm{O}_{3}$ coated $\mathrm{MoS}_{2}$ nanospheres (curve (b)).

S-Twin TEM) at an accelerating voltage of $210 \mathrm{kV}$. The optical properties of the nanoparticles were studied using UVvisible spectroscopy (Cary 5000 UV-Vis spectrophotometry). Thermogravimetric (TG) and differential thermal analysis (DTA) were carried out on a SDT Q600 thermogravimetric analyzer under $\mathrm{N}_{2}$ flow at a rate of $30 \mathrm{~cm}^{3} / \mathrm{min}$. The furnace temperature was increased from room temperature to $900^{\circ} \mathrm{C}$ at a heating rate of $10^{\circ} \mathrm{C}$ per minute. The purity of the final product was examined by X-ray photoelectron spectroscopy (XPS, Thermo Scientific K-alpha surface analysis instrument).

The photocatalytic experiments were carried out at the natural $\mathrm{pH}$ of the $\mathrm{RhB}$ organic pollutant solution. The photoreactor has a $150-\mathrm{W}$ mercury lamp with a main emission wavelength of $254 \mathrm{~nm}$ as an internal light source, which is surrounded by a quartz vessel. The suspension includes 


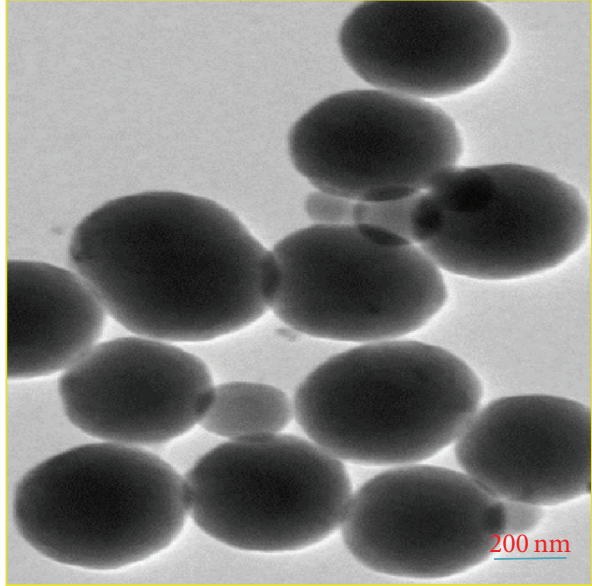

(a)

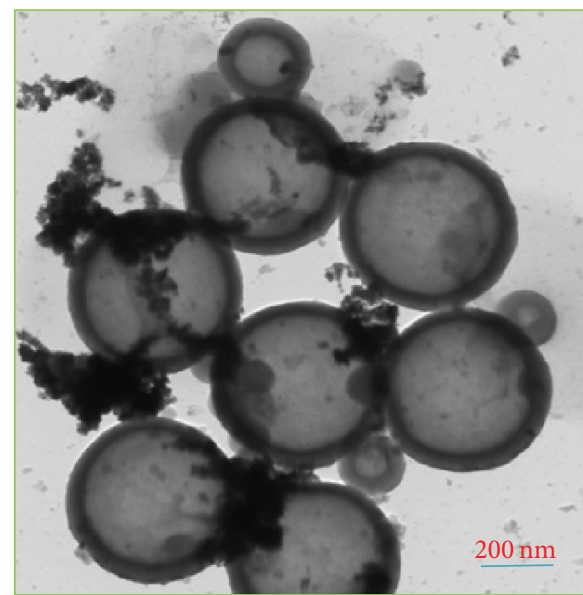

(c)

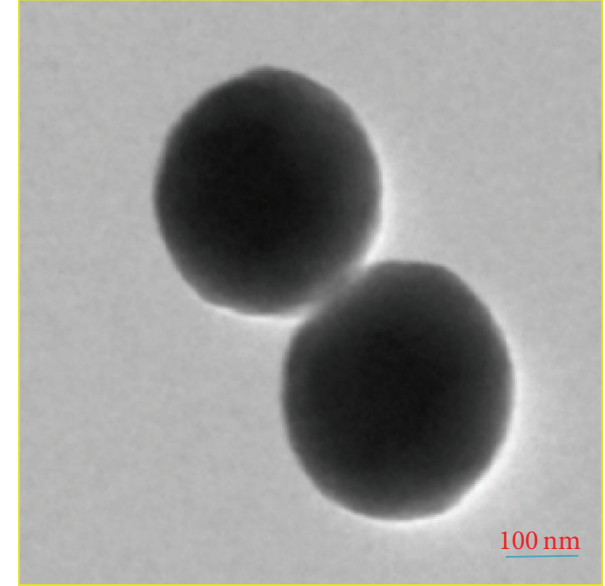

(b)

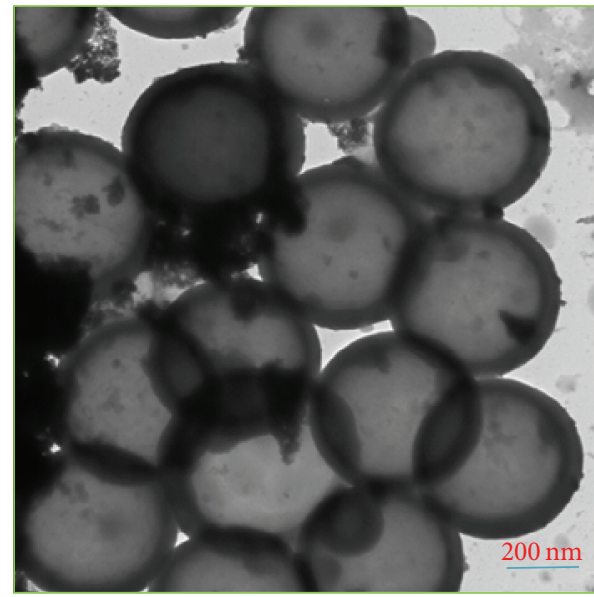

(d)

Figure 3: TEM images of ((a), (b)) $\mathrm{MoS}_{2}$ nanospheres, ((c), (d)) $\mathrm{Al}_{2} \mathrm{O}_{3}$-coated $\mathrm{MoS}_{2}$ nanospheres.

the $\mathrm{Al}_{2} \mathrm{O}_{3}$-decorated $\mathrm{MoS}_{2}$ nanosphere catalyst and aqueous $\mathrm{RhB}(100 \mathrm{~mL}, 10 \mathrm{mg} / \mathrm{L})$, which completely surrounds the light source. Before irradiation, the suspension was stirred in the dark for $30 \mathrm{~min}$ to obtain a good dispersion and to ensure adsorption-desorption equilibrium between the organic pollutant molecules and the catalyst. During light irradiation, the samples of the reaction solution were collected at given intervals and examined using an optical spectrophotometer.

\section{Results and Discussions}

The XRD patterns of $\mathrm{MoS}_{2}$ nanospheres and $\mathrm{Al}_{2} \mathrm{O}_{3}$-coated $\mathrm{MoS}_{2}$ nanospheres were shown in Figure 2. In case of $\mathrm{MoS}_{2}$ sphere sample exhibits three well-resolved peaks which can be indexed as the 002,103 , and 110 reflections of the $2 \mathrm{D}$ hexagonal structure, which is matched with JCPDS number 77-1716. On the other hand, XRD pattern of $\mathrm{Al}_{2} \mathrm{O}_{3}$-coated $\mathrm{MoS}_{2}$ sample exhibits hexagonal structure, whereas $\mathrm{Al}_{2} \mathrm{O}_{3}$ layer is been crystallized, which is corresponding to JCPDS number 78-2426. The coexisting peaks of $\mathrm{Al}_{2} \mathrm{O}_{3}$-coated $\mathrm{MoS}_{2}$ nanospheres corresponding to the $012,110,006,024$, and 018 crystal plane are ascribed to $\gamma-\mathrm{Al}_{2} \mathrm{O}_{3}$ phase for the sintered samples at $450^{\circ} \mathrm{C}[21,22]$. The diffraction lines characteristics of $\mathrm{MoS}_{2}$ and $\mathrm{Al}_{2} \mathrm{O}_{3}$ and no other elemental peaks were detected.

The morphology of the $\mathrm{MoS}_{2}$ nanospheres and $\mathrm{Al}_{2} \mathrm{O}_{3}$ coated $\mathrm{MoS}_{2}$ nanospheres was examined using TEM, as shown in Figure 3. $\mathrm{MoS}_{2}$ nanospheres were coated with $\mathrm{Al}_{2} \mathrm{O}_{3}$ using $\mathrm{Al}\left(\mathrm{NO}_{3}\right)_{3} \cdot 9 \mathrm{H}_{2} \mathrm{O}$ as a precursor via a hydrothermal method. For better understanding of the morphology of the composite, we initially tested the $\mathrm{MoS}_{2}$ nanospheres without using $\mathrm{Al}$ precursors. The morphology of the $\mathrm{MoS}_{2}$ nanospheres is shown in Figures 3(a) and 3(b). The $\mathrm{MoS}_{2}$ materials reveal typical sphere-like morphology with several nanometers in diameter. On the other hand, the $\mathrm{MoS}_{2}$ spheres obtained using $\mathrm{Al}$ precursors retained their spherical morphology with the formation of a uniform layer, forming a core-shell structure (Figures 3(c) and 3(d)). The average thickness of the $\mathrm{Al}_{2} \mathrm{O}_{3}$ layer around the periphery of the $\mathrm{MoS}_{2}$ is about $15 \mathrm{~nm}$.

Further understanding of the structural and compositional characterizations of $\mathrm{Al}_{2} \mathrm{O}_{3}$-coated $\mathrm{MoS}_{2}$ nanospheres was obtained using HRTEM. The HRTEM image of an edge 


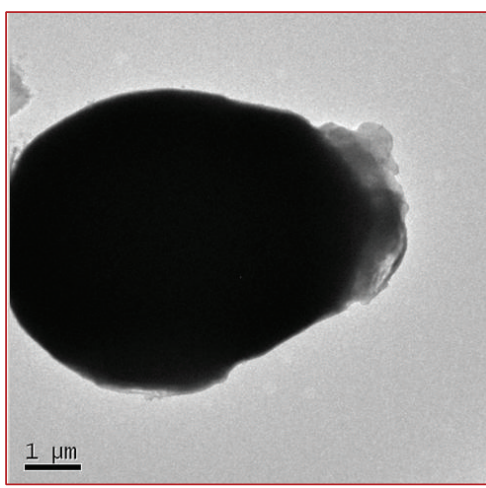

(a)

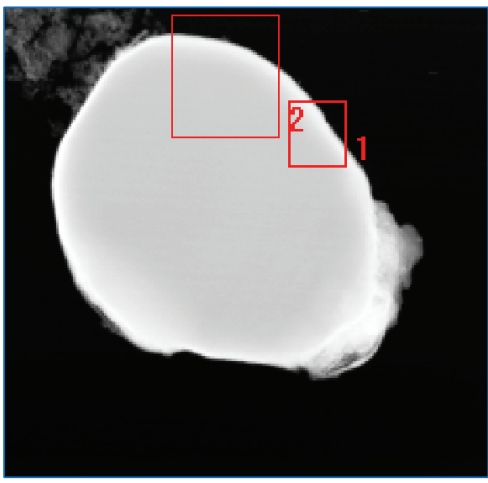

(d)

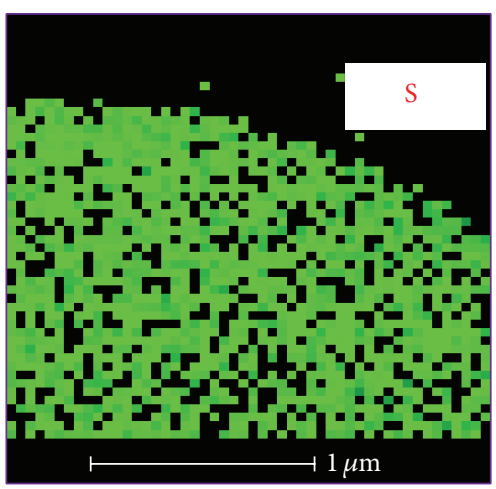

(g)

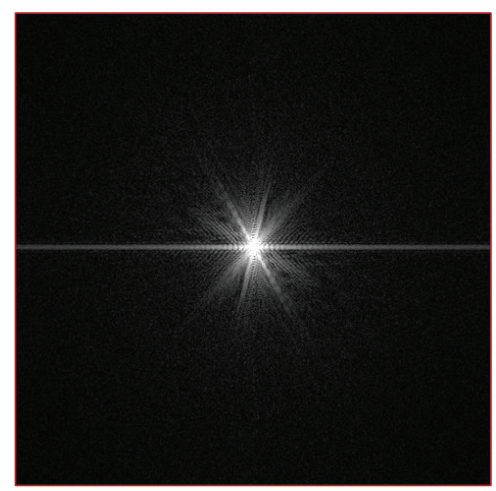

(b)

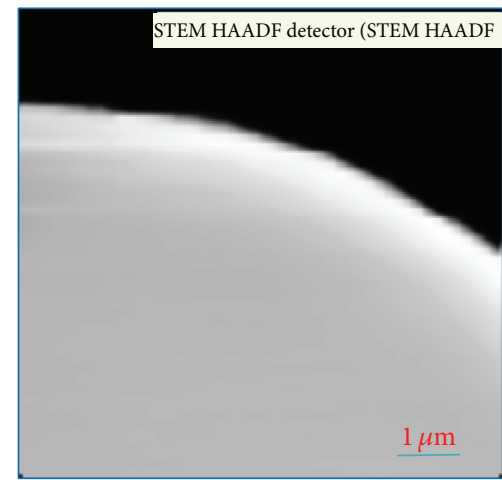

(e)

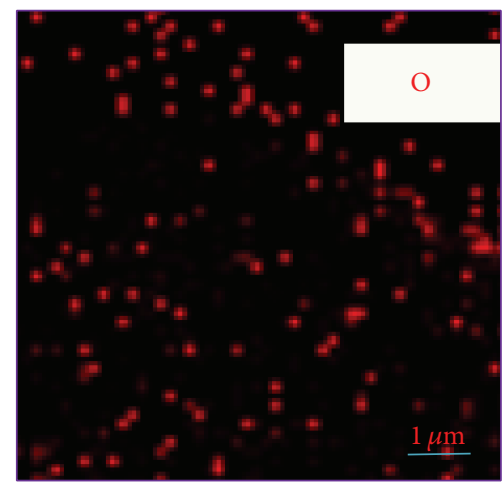

(h)

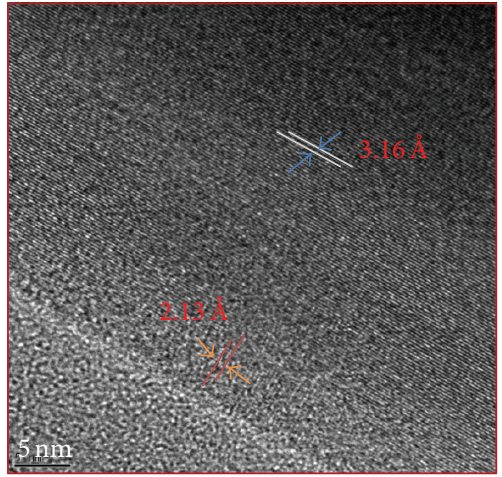

(c)

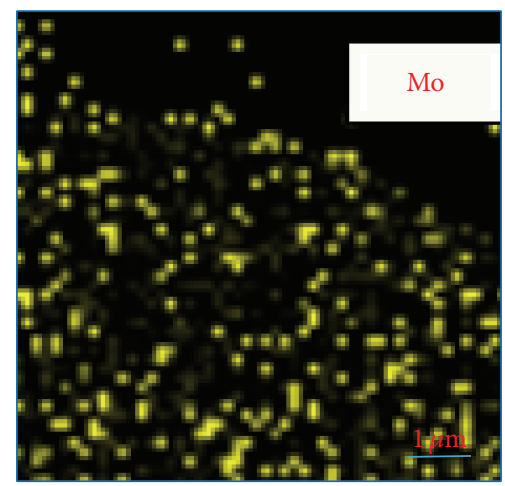

(f)

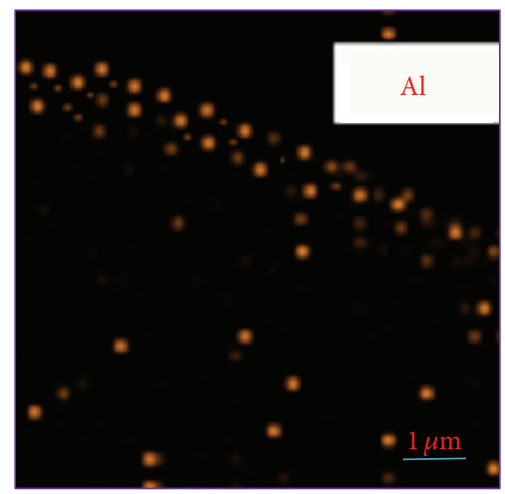

(i)

Figure 4: HR-TEM images ((a)-(e)) of $\mathrm{Al}_{2} \mathrm{O}_{3}$-coated $\mathrm{MoS}_{2}$ nanospheres, ((f)-(i)) HR-TEM elemental mapping images of $\mathrm{Al}_{2} \mathrm{O}_{3}$-coated $\mathrm{MoS}_{2}$ nanospheres.

portion of a core-shell sphere is shown in Figures 4(a)-4(d). The HRTEM image (Figure 4(a)) confirms that the $\mathrm{Al}_{2} \mathrm{O}_{3}$ colloids are aggregated on the $\mathrm{MoS}_{2}$ nanospheres. The lattice fringes of the core-shell structure with lattice spacings of about 0.213 and $0.316 \mathrm{~nm}$ could be attributed to the (103) and (110) planes of $2 \mathrm{H}-\mathrm{MoS}_{2}$, respectively. Figures 4(e)-4(i) show typical energy dispersive X-ray spectrometer (EDX) elemental mappings of the core-shell spheres of various elements in the core-shell structure, along with its TEM image. The Mo, S, $\mathrm{Al}$, or $\mathrm{O}$ signals are predominantly distributed in the core and shell regions within the selected area, respectively. Figure 5 shows the EDX mapping of $\mathrm{Al}_{2} \mathrm{O}_{3}$-coated $\mathrm{MoS}_{2}$ nanospheres. There are no other traces observed.

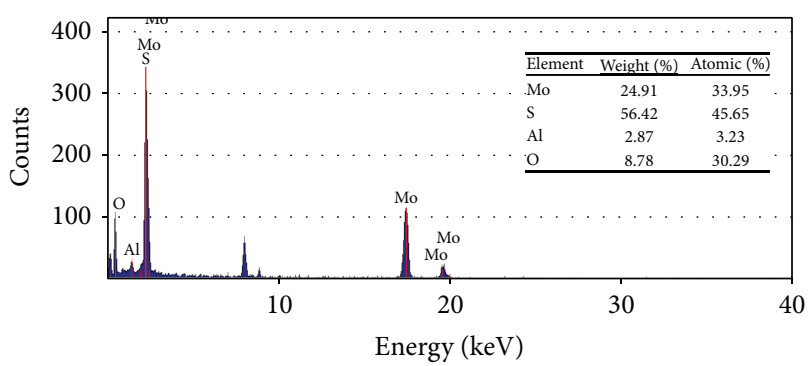

- 16.20.00 acquire EDX acquire HAADF area 1

FIgURE 5: HR-TEM EDX data of $\mathrm{Al}_{2} \mathrm{O}_{3}$-coated $\mathrm{MoS}_{2}$ nanospheres. 


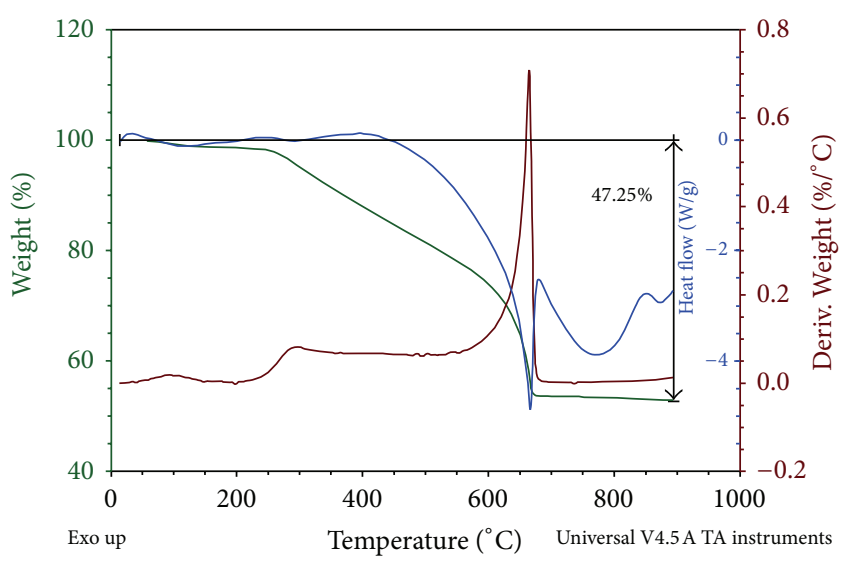

Figure 6: TG-DTA analysis of $\mathrm{Al}_{2} \mathrm{O}_{3}$-coated $\mathrm{MoS}_{2}$ nanospheres.

Thermogravimetric and differential thermal analysis (TG-DTA) was conducted to quantitatively determine the $\mathrm{Al}_{2} \mathrm{O}_{3}$ content present in the $\mathrm{Al}_{2} \mathrm{O}_{3}$-coated $\mathrm{MoS}_{2}$ nanospheres, as shown in Figure 6. The initial weight loss below $220^{\circ} \mathrm{C}$ is ascribed to the evaporation of physically absorbed water from the product, whereas the weight loss between 550 and $680^{\circ} \mathrm{C}$ that occurred with an exothermic peak at $650^{\circ} \mathrm{C}$ could essentially be attributed to the decomposition and separation of the $\mathrm{Al}_{2} \mathrm{O}_{3}$ layer. The $\mathrm{Al}_{2} \mathrm{O}_{3}$ content was estimated to be approximately $47.25 \%$ by weight.

The electronic states of the metals and sulfur in the $\mathrm{Al}_{2} \mathrm{O}_{3}$ coated $\mathrm{MoS}_{2}$ nanospheres were tested using XPS, as shown in Figures 7(a)-7(e). The XPS survey spectra of the $\mathrm{Al}_{2} \mathrm{O}_{3}$ coated $\mathrm{MoS}_{2}$ nanospheres are shown in Figure 7(a). The Al2p XPS spectra were estimated for the $\mathrm{Al}_{2} \mathrm{O}_{3}$-coated $\mathrm{MoS}_{2}$ nanospheres to examine the chemical state of Al. The Mo3d, S2P, Al2p, and O1s peaks from the $\mathrm{Al}_{2} \mathrm{O}_{3}$-coated $\mathrm{MoS}_{2}$ sphere sample (Figures $7(\mathrm{~b})-7(\mathrm{e})$ ) show no presence of addition chemical states. The binding energy difference $\Delta E$ between the Al2p and 2s levels is $53.34 \mathrm{eV}$ for the $\mathrm{Al}_{2} \mathrm{O}_{3}$-coated $\mathrm{MoS}_{2}$ nanospheres. The XPS results strongly indicate that $\mathrm{Al}$ species interacted with the $\mathrm{MoS}_{2}$ nanospheres and are preferentially formed in the $\mathrm{Al}_{2} \mathrm{O}_{3}-\mathrm{MoS}_{2}$ composite using $\mathrm{Al}\left(\mathrm{NO}_{3}\right)_{3} \cdot 9 \mathrm{H}_{2} \mathrm{O}$ as a precursor. The Al2p and O1s peaks were centered at $74.45 \mathrm{eV}$ and $532.36 \mathrm{eV}$, as described elsewhere [23].

The S2p spectrum shows a supplementary peak at $164.58 \mathrm{eV}$ coexisting with an O1s peak, which is ascribed to the oxidation of sulfur. The formation of covalent S-O bonding without breakage of the Mo-S bond is likely due to the oxidation state of sulfur. No S-O bond is observed in the S2s spectrum, which suggests that only the top surface of sulfur atoms of $\mathrm{MoS}_{2}$ are oxygen functionalized. This is good evidence that the $\mathrm{Al}_{2} \mathrm{O}_{3}$ formed a bond with $\mathrm{MoS}_{2}$ nanospheres, resulting in the formation of the core-shell structure. The XPS binding energies $\Delta E 1$ (Mo $2 \mathrm{p}_{3 / 2}-\mathrm{S} 2 \mathrm{p}_{3 / 2}$ ) and $\Delta E 2\left(\right.$ Mo $\left.3 \mathrm{~d}_{5 / 2}-\mathrm{S} 2 \mathrm{p}_{3 / 2}\right)$ of the $\mathrm{Al}_{2} \mathrm{O}_{3}$-coated $\mathrm{MoS}_{2}$ nanospheres are 70.3 and $67.09 \mathrm{eV}$, respectively.

The UV-Vis spectrum of the synthesized $\mathrm{Al}_{2} \mathrm{O}_{3}$-coated $\mathrm{MoS}_{2}$ nanospheres is shown in Figure 8(a). The absorption edge at $275 \mathrm{~nm}$ could be attributed to the absorption of $\mathrm{Al}_{2} \mathrm{O}_{3}-\mathrm{MoS}_{2}$ in the UV region. The absorption spectrum shows two absorption edges at 603 and $660 \mathrm{~nm}$. These are attributed to excitonic transitions of the Brillouin region at the $K$ point, which is consistent with an earlier report [24]. The energy separation between the two absorption peaks (at 603 and $660 \mathrm{~nm}$ ) is $0.15 \mathrm{eV}$ due to the spin-orbit splitting at the $K$ point at the surface of the valence band [24]. Moreover, there is weak absorbance in the visible region at a wavelength of $425 \mathrm{~nm}$. The UV-absorption behavior of $\mathrm{MoS}_{2}$ strongly depends on its size due to quantum effects [25]. For example, the absorption edges of $\mathrm{MoS}_{2}$ nanoparticles with average diameters of about 4.5 and $9 \mathrm{~nm}$ have edges at 470 and $700 \mathrm{~nm}$, respectively, in the visible light region [26]. In contrast, bulk $\mathrm{MoS}_{2}$ (with a band gap of $1.23 \mathrm{eV}$ ) has an absorption peak at around $1040 \mathrm{~nm}$ [25]. $\mathrm{MoS}_{2}$-based composites have diverse absorption edges with respect to their dimensional parameters [26].

The indirect band gap is estimated using the Tauc equation with optical absorption data for near the band edge [24]: $(\alpha h \nu)^{1 / 2}=A\left(h \nu-E_{g}\right)$. The band gaps $\left(E_{g}\right)$ are determined from extrapolation of a linear fit onto the $x$-axis. A plot of $(\alpha h v)^{1 / 2}$ versus the photon energy $(h \nu)$ and the intercept of the tangent to the $x$-axis gives the band gap of the $\mathrm{Al}_{2} \mathrm{O}_{3}$ coated $\mathrm{MoS}_{2}$ nanospheres, as shown in Figure 8(b). The band gap energy of $\mathrm{Al}_{2} \mathrm{O}_{3}$-coated $\mathrm{MoS}_{2}$ nanospheres was found to be $2.42 \mathrm{eV}$.

Figure 9 shows the progressive changes of the UVVis absorption spectra of $\mathrm{RhB}$ solution in the presence of $\mathrm{Al}_{2} \mathrm{O}_{3}$-coated $\mathrm{MoS}_{2}$ nanosphere catalyst under UV light as a function of time. The strong absorption peak of the $\mathrm{RhB}$ solution at $564 \mathrm{~nm}$ gradually decreases from dark conditions to $60 \mathrm{~min}$, and the color of the solution turns from pink to colorless at the end of the photodegradation process. Figure 10 shows the photodegradation efficiency of $\mathrm{MoS}_{2}$ nanospheres and $\mathrm{Al}_{2} \mathrm{O}_{3}$-coated $\mathrm{MoS}_{2}$ nanosphere catalysts under UV light in $\mathrm{RhB}$ solution. The results are shown as the relative concentration $\left(C / C_{0}\right)$ as a function of irradiation time, where $C_{0}$ and $C(\mathrm{mg} / \mathrm{L})$ are the initial and final concentrations of the pollutant solution.

A blank experiment was carried out in the absence of photocatalyst for comparison, which showed no obvious change in the $\mathrm{RhB}$ concentration within $60 \mathrm{~min}$. The introduction of $\mathrm{MoS}_{2}$ nanospheres and $\mathrm{Al}_{2} \mathrm{O}_{3}$-coated $\mathrm{MoS}_{2}$ nanosphere catalysts can greatly enhance the photocatalytic activity under UV light. Interestingly, the $\mathrm{Al}_{2} \mathrm{O}_{3}$-coated $\mathrm{MoS}_{2}$ nanosphere photocatalysts displayed much higher photodegradation performance than the $\mathrm{MoS}_{2}$ nanospheres, and more than $97 \%$ of the $\mathrm{RhB}$ was degraded within $60 \mathrm{~min}$. The presence of $\mathrm{Al}_{2} \mathrm{O}_{3}$ coated $\mathrm{MoS}_{2}$ nanospheres plays a key role in the photocatalytic degradation process. The significant enhancement in photoactivity can be ascribed to the favorable van der Waals surfaces of the $\mathrm{Al}_{2} \mathrm{O}_{3}$-coated $\mathrm{MoS}_{2}$ nanospheres.

Figure 11 shows a kinetic plot of the photocatalytic degradation of $\mathrm{RhB}$ over time under UV light irradiation as $\ln \left(C / C_{0}\right)$. The removal efficiency of the $\mathrm{Al}_{2} \mathrm{O}_{3}$-coated $\mathrm{MoS}_{2}$ nanospheres was much faster than that of the $\mathrm{MoS}_{2}$ nanosphere catalyst. To understand the photostability and reusability of the photocatalyst, four successive recycling tests of the photocatalysts were done for the degradation of $\mathrm{RhB}$ under UV light, as shown in Figure 12. There were no 


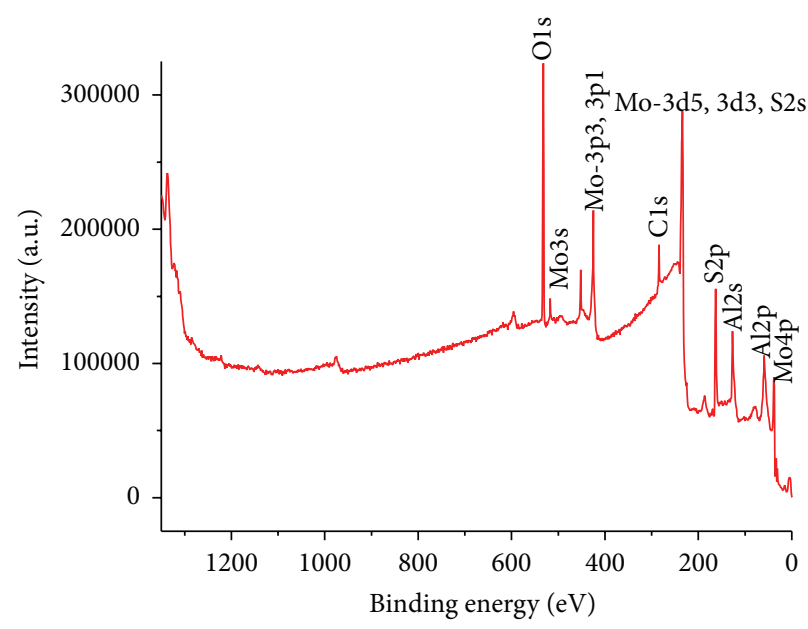

(a)

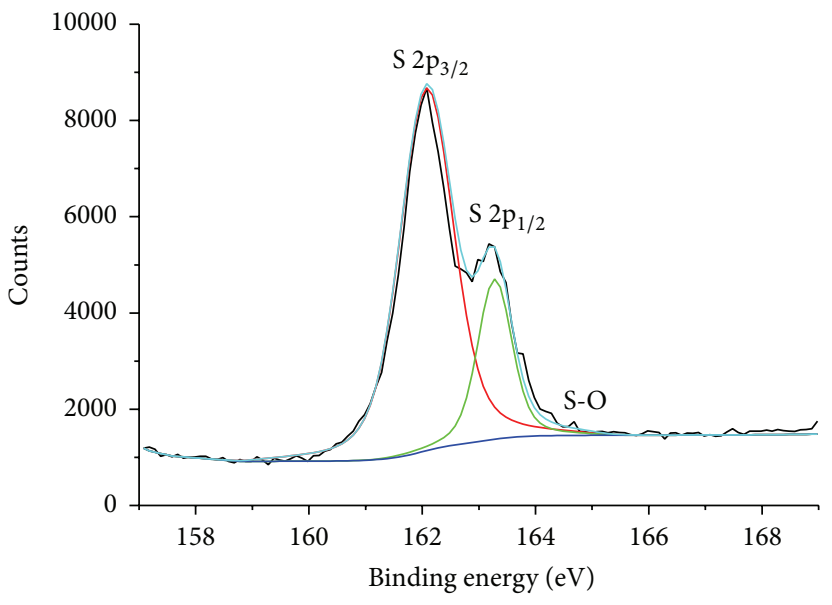

(c)

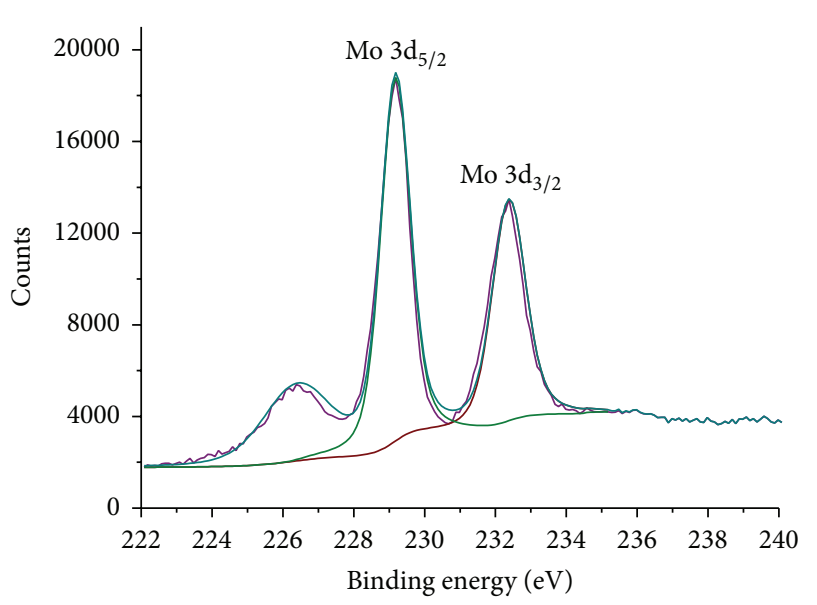

(b)

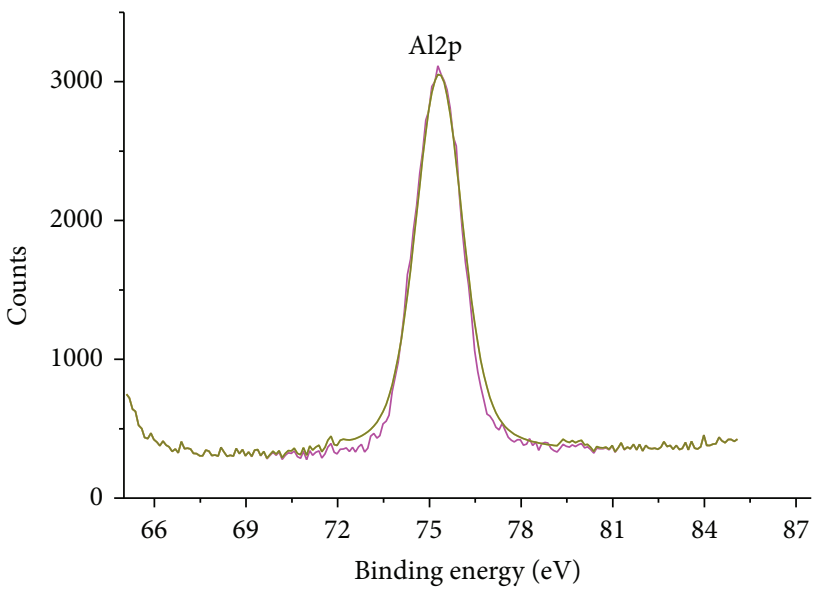

(d)

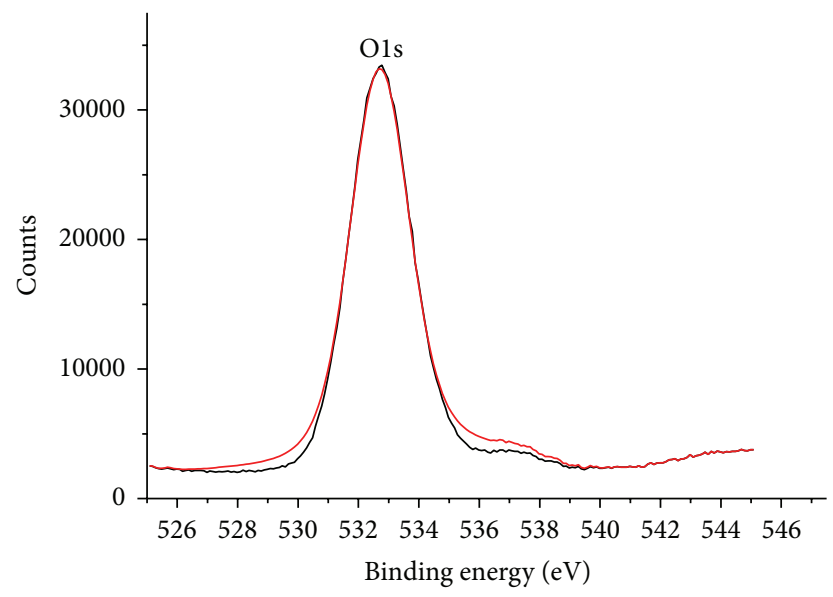

(e)

Figure 7: XPS data of $\mathrm{Al}_{2} \mathrm{O}_{3}$-coated $\mathrm{MoS}_{2}$ nanospheres: (a) survey spectrum, (b) Mo 3d, (c) S2p, (d) Al2p, and (e) O1s.

significant changes in photocatalytic activity, which shows the steadiness of the degradation efficiency of $\mathrm{RhB}$ solution. This result implies that the $\mathrm{Al}_{2} \mathrm{O}_{3}$-coated $\mathrm{MoS}_{2}$ nanosphere photocatalysts have high stability during the photocatalytic oxidation of the pollutant molecules and are reusable.
The catalytic activity increased with the $\mathrm{Al}_{2} \mathrm{O}_{3}$-coated $\mathrm{MoS}_{2}$ nanospheres. Figure 13 shows the RhB removal efficiency of the $\mathrm{Al}_{2} \mathrm{O}_{3}$-coated $\mathrm{MoS}_{2}$ photocatalytic nanospheres with $5 \mathrm{mg}$ of catalyst and $50 \mathrm{~mL}$ of $10 \mathrm{mgL}^{-1} \mathrm{RhB}$ solution. The pollutant removal efficiency and the adsorption amount 


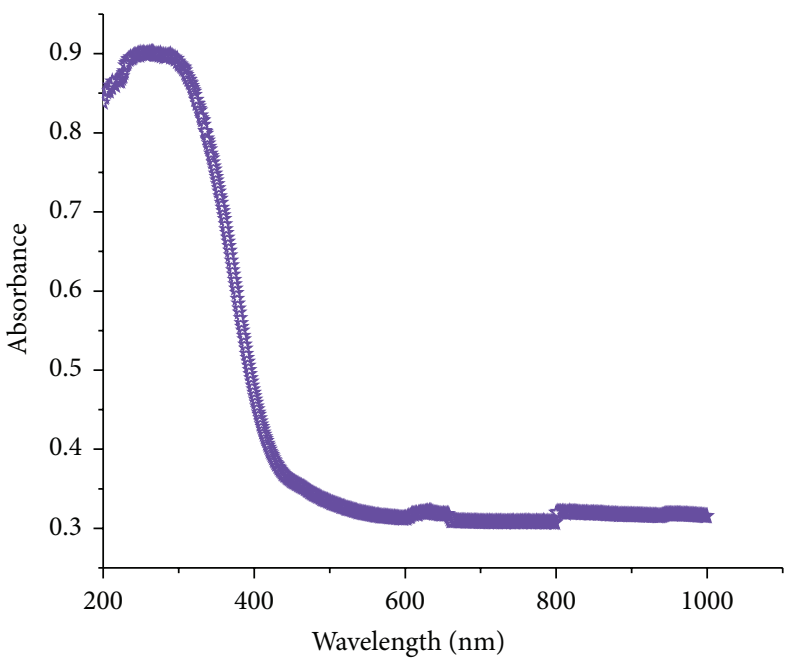

(a)

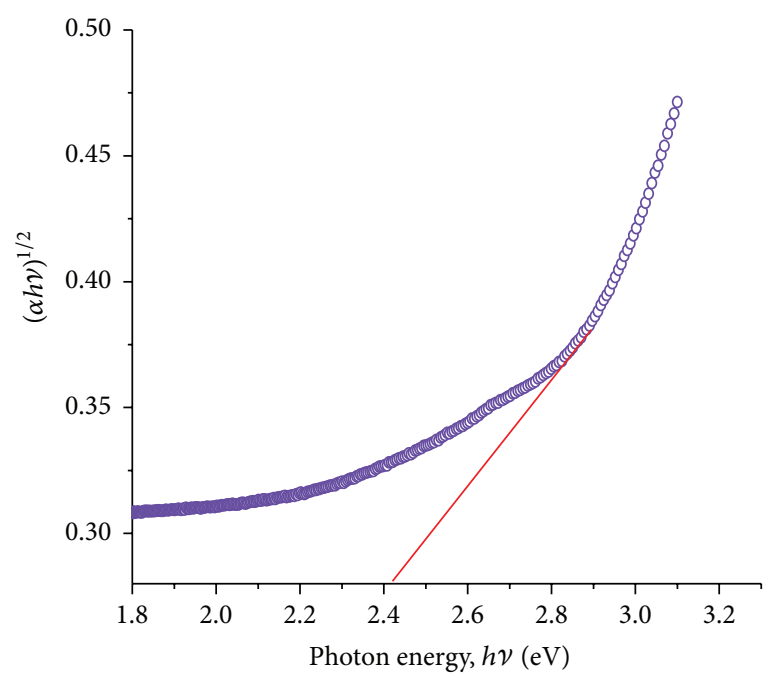

(b)

Figure 8: (a) UV-Vis light spectra of the $\mathrm{Al}_{2} \mathrm{O}_{3}$-coated $\mathrm{MoS}_{2}$ nanospheres, (b) Tauc plots of $\mathrm{Al}_{2} \mathrm{O}_{3}$-coated $\mathrm{MoS}_{2}$ nanospheres.

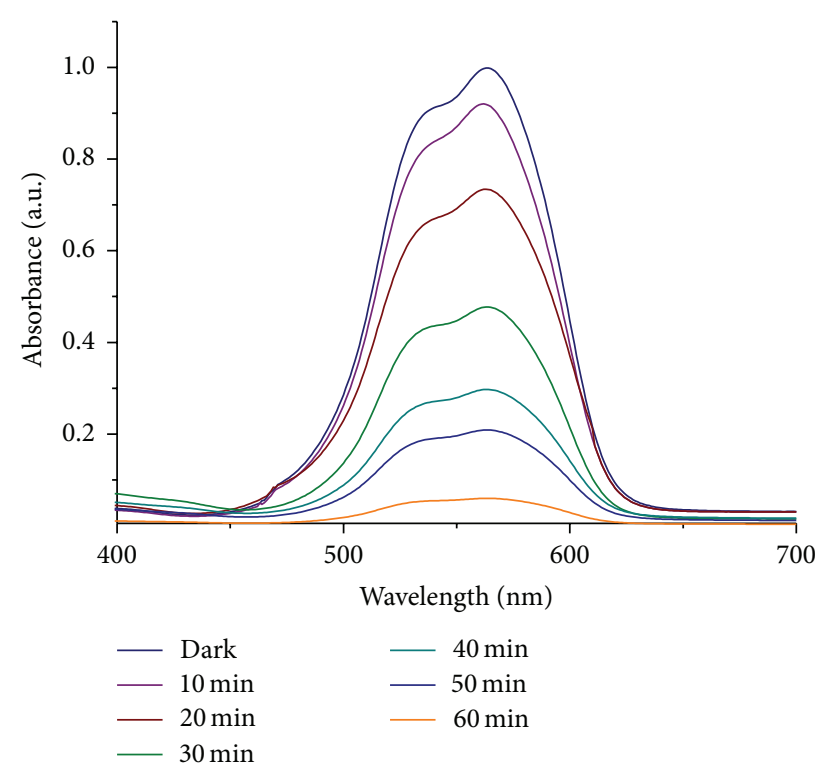

Figure 9: Time-dependent UV-Vis absorbance spectra of $\mathrm{Al}_{2} \mathrm{O}_{3}$ coated $\mathrm{MoS}_{2}$ nanospheres of the rhodamine $\mathrm{B}$ solution samples at different times.

at equilibrium (qe) were calculated using the following equation:

$$
\text { Pollutant removal efficiency }(\mathrm{PR} \%)=\frac{100\left(C_{0}-C\right)}{C_{0}},
$$

where $C_{0}$ and $C(\mathrm{mg} / \mathrm{L})$ are the initial and final concentrations of the pollutant, respectively, $V$ is the volume of the pollutant solution, and $m$ (g) is the mass of the catalyst. The $\mathrm{Al}_{2} \mathrm{O}_{3}$-coated $\mathrm{MoS}_{2}$ nanospheres exhibit high $\mathrm{RhB}$ removal efficiency (95\%), in contrast to the (69\%) $\mathrm{MoS}_{2}$ nanosphere sample. It is well known that catalytic ability increases with

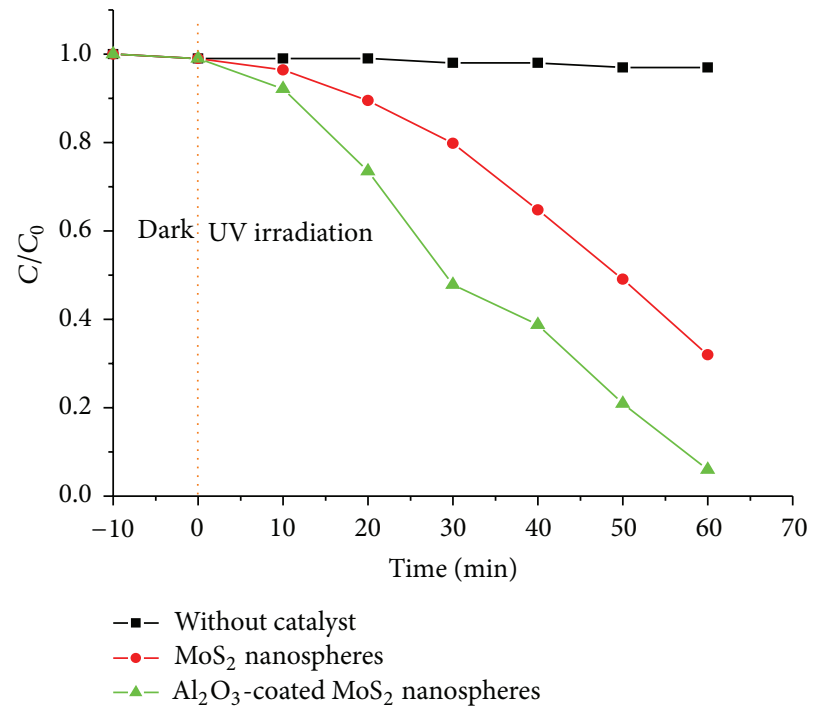

Figure 10: Photodegradation rate of the rhodamine B under UV light and light irradiation time for without catalyst, $\mathrm{MoS}_{2}$ nanospheres, and $\mathrm{Al}_{2} \mathrm{O}_{3}$-coated $\mathrm{MoS}_{2}$ nanospheres.

increasing content of the catalyst with respect to processing time and other environmental conditions like temperature and $\mathrm{pH}$. In this work, the degradation rate of the $\mathrm{RhB}$ solution also increased with increasing catalyst content due to the small particle size and good dispersibility of the $\mathrm{Al}_{2} \mathrm{O}_{3}$-coated $\mathrm{MoS}_{2}$ nanoparticles, which facilitate electron migration between the catalyst and pollutant. The $\mathrm{Al}_{2} \mathrm{O}_{3}$ coated $\mathrm{MoS}_{2}$ nanospheres exhibit high catalytic activity due to the high dispersibility of the $\mathrm{Al}_{2} \mathrm{O}_{3}$ coating around the $\mathrm{MoS}_{2}$ nanospheres, which secured more efficient charge transfer between the $\mathrm{MoS}_{2}$ and $\mathrm{Al}_{2} \mathrm{O}_{3}$.

The $\mathrm{MoS}_{2}$ behaves as the photoactive center, which is generating excited photoelectron pairs under UV irradiation, 


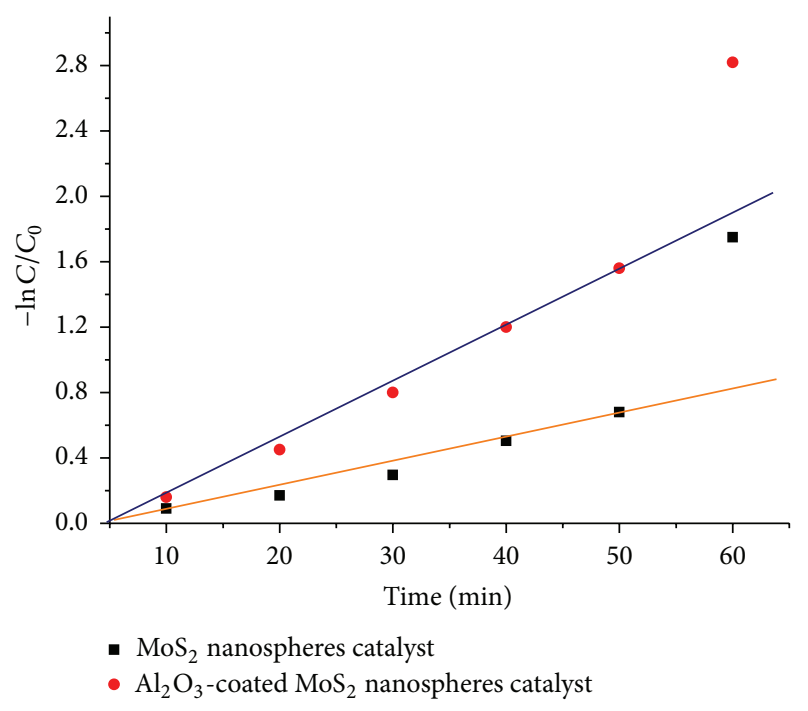

FIGURE 11: The kinetic plot of $\mathrm{Al}_{2} \mathrm{O}_{3}$-coated $\mathrm{MoS}_{2}$ nanospheres photocatalytic degradation of rhodamine $\mathrm{B}$ under UV light irradiation.

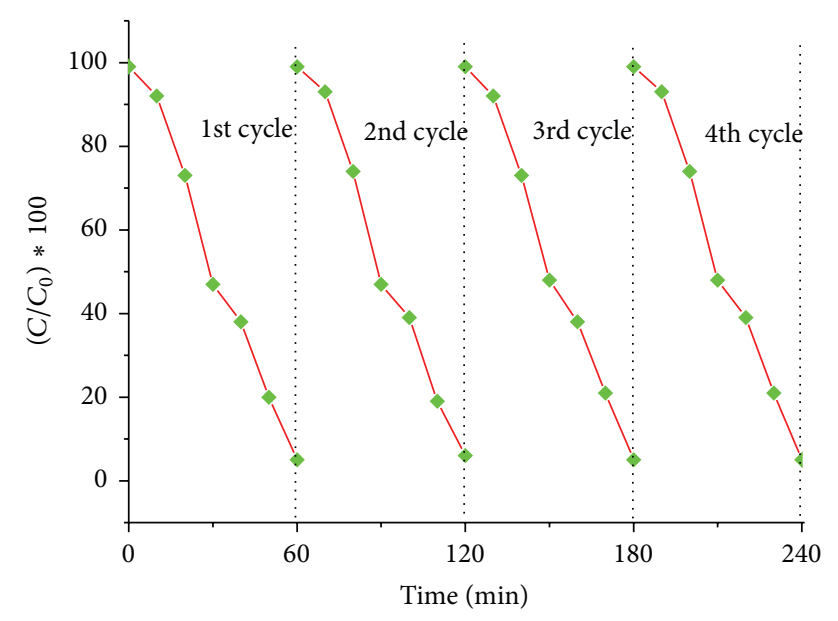

FIGURE 12: Recycling photocatalytic degradation of rhodamine $\mathrm{B}$ in the presence of $\mathrm{Al}_{2} \mathrm{O}_{3}$-coated $\mathrm{MoS}_{2}$ nanospheres photocatalytic under UV light irradiation.

while the $\mathrm{Al}_{2} \mathrm{O}_{3}$ provides better adsorption sites in the vicinity of the $\mathrm{MoS}_{2}$. The presence of insulating layers of $\mathrm{Al}_{2} \mathrm{O}_{3}$ on the surface of $\mathrm{MoS}_{2}$ nanospheres suppresses the unwanted charge recombination, thus enhancing the photocatalytic activity. The greater photocatalytic activity of $\mathrm{Al}_{2} \mathrm{O}_{3}$-coated $\mathrm{MoS}_{2}$ nanospheres can be explained as follows. The HRTEM mapping results indicated that the periphery of the $\mathrm{MoS}_{2}$ was covered with $\mathrm{Al}_{2} \mathrm{O}_{3}$. Under UV light irradiation, both $\mathrm{MoS}_{2}$ and $\mathrm{Al}_{2} \mathrm{O}_{3}$ are photoexcited, and holes and electrons form in the valance band and conduction band. The photogenerated holes and electrons are transferred within the valance and conduction bands of both the $\mathrm{MoS}_{2}$ and $\mathrm{Al}_{2} \mathrm{O}_{3}$ materials. This tendency helps to extend the charge carriers. The excited electrons and holes react with dissolved oxygen in the water or directly oxidize the pollutant molecules to form oxide

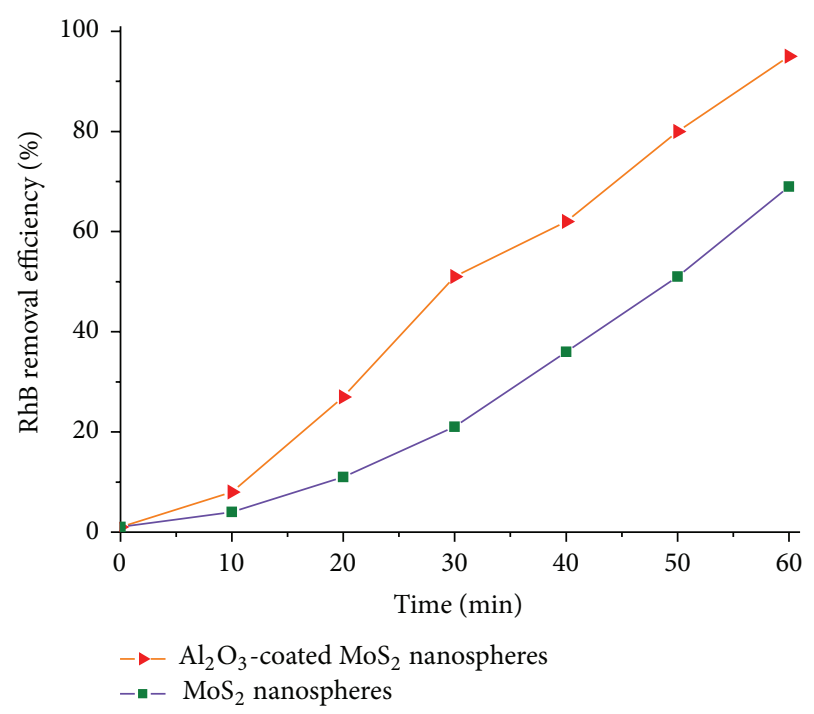

FIGURE 13: RhB removal efficiency of $\mathrm{Al}_{2} \mathrm{O}_{3}$-coated $\mathrm{MoS}_{2}$ nanospheres photocatalytic, adsorption conditions: $5 \mathrm{mg}$ catalyst, $50 \mathrm{~mL}$ $10 \mathrm{mgL}^{-1} \mathrm{RhB}$ solution (conditions: $5 \mathrm{mg}$ of catalyst and $50 \mathrm{~mL}$ of $10 \mathrm{mgL}^{-1}$ RhB solution).

radicals $\left(\mathrm{O}_{2}{ }^{--}\right)$and hydroxyl radicals $\left({ }^{\circ} \mathrm{OH}\right)$, which are responsible for the degradation of $\mathrm{RhB}$.

A possible mechanism for formation of $\mathrm{MoS}_{2} @ \mathrm{Al}_{2} \mathrm{O}_{3}$ core-shell structure is suggested involving $\mathrm{MoS}_{2}$ spheres acting as a template for the formation of the coated nanospheres. Due to hydrothermal reactions between the metal-oxoanions and surfactant, cations form a composite phase at the surfactant/inorganic interfaces. Thus, nucleation domains were formed during the hydrothermal reaction between $\mathrm{MoO}_{4}{ }^{2-}$ and $\mathrm{S}^{2-}$ and formed $\mathrm{MoS}_{2}$ spheres. In this manner, the diameter of the nanospheres is no longer limited by the micelle dimensions. A spherical phase of $\mathrm{MoS}_{2}$ is formed during hydrothermal treatment under the synthetic conditions, in which L-cysteine acts as a sulfur source to stabilize the spherical organization of Mo and S species. The $\mathrm{Al}$ species of the precursor solution can absorb to the surface of $\mathrm{MoS}_{2}$ spheres, and layer upon layer is formed by the electrostatic interaction. The TSC could be considered a crucial component for the growth mechanism of $\mathrm{Al}_{2} \mathrm{O}_{3}$ coating because it acts as a capping agent for the formation of the coating surface on the $\mathrm{MoS}_{2}$ nanospheres. The complete synthetic mechanism is expressed in Figure 1.

\section{Conclusions}

$\mathrm{Al}_{2} \mathrm{O}_{3}$-coated $\mathrm{MoS}_{2}$ nanospheres were successfully synthesized using a simple hydrothermal method. The $\mathrm{Al}_{2} \mathrm{O}_{3}$ shell materials serve as additional electron sources that can significantly recover the electron conduction in $\mathrm{MoS}_{2}$, which favors the photodegradation of the pollutant. We revealed the appropriate selection of surfactants that could facilitate the adherence of $\mathrm{Al}$ species to the surfaces of the cores. Hydrothermally synthesized $\mathrm{Al}_{2} \mathrm{O}_{3}$-coated $\mathrm{MoS}_{2}$ nanosphere catalysts show photocatalytic activity higher than that of the 
$\mathrm{MoS}_{2}$ nanosphere catalyst due to the enhanced crystallites with high metal content, which minimize the poisoning effect of sulfur by the chemisorption process.

\section{Conflict of Interests}

The authors declare that there is no conflict of interests regarding the publication of this paper.

\section{Acknowledgments}

This research was supported by the Basic Science Research Program through the National Research Foundation of Korea (NRF) and funded by the Ministry of Science, ICT, and Future Planning (2014R1A2A2A01007081).

\section{References}

[1] H. S. S. Ramakrishna Matte, A. Gomathi, A. K. Manna et al., " $\mathrm{MoS}_{2}$ and $\mathrm{WS}_{2}$ analogues of graphene," Angewandte Chemie International Edition, vol. 49, no. 24, pp. 4059-4062, 2010.

[2] Y. Li, H. Wang, L. Xie, Y. Liang, G. Hong, and H. Dai, " $\mathrm{MoS}_{2}$ nanoparticles grown on graphene: an advanced catalyst for the hydrogen evolution reaction," Journal of the American Chemical Society, vol. 133, no. 19, pp. 7296-7299, 2011.

[3] J. J. Lee, H. Kim, and S. H. Moon, "Preparation of highly loaded, dispersed $\mathrm{MoS}_{2} / \mathrm{Al}_{2} \mathrm{O}_{3}$ catalysts for the deep hydrodesulfurization of dibenzothiophenes," Applied Catalysis B: Environmental, vol. 41, no. 1-2, pp. 171-180, 2003.

[4] D. Song, M. Li, Y. Jiang et al., "Facile fabrication of $\mathrm{MoS}_{2}$ / PEDOT-PSS composites as low-cost and efficient counter electrodes for dye-sensitized solar cells," Journal of Photochemistry and Photobiology A: Chemistry, vol. 279, pp. 47-51, 2014.

[5] C. Zhang, H. B. Wu, Z. Guo, and X. W. Lou, "Facile synthesis of carbon-coated $\mathrm{MoS}_{2}$ nanorods with enhanced lithium storage properties," Electrochemistry Communications, vol. 20, pp. 7-10, 2012.

[6] H.-H. Chien, K.-J. Ma, S. V. P. Vattikuti, C.-H. Kuo, C.-B. Huo, and C.-L. Chao, "Tribological behaviour of $\mathrm{MoS}_{2} / \mathrm{Au}$ coatings," Thin Solid Films, vol. 518, no. 24, pp. 7532-7534, 2010.

[7] M. Donarelli, S. Prezioso, F. Perrozzi et al., "Response to $\mathrm{NO}_{2}$ and other gases of resistive chemically exfoliated $\mathrm{MoS}_{2}$-based gas sensors," Sensors and Actuators B: Chemical, vol. 207, pp. 602-613, 2015.

[8] Y. Shi, Y. Wang, J. I. Wong et al., "Self-assembly of hierarchical $\mathrm{MoS}_{x} / \mathrm{CNT}$ nanocomposites $(2<\mathrm{x}<3)$ : towards high performance anode materials for lithium ion batteries," Scientific Reports, vol. 3, article 2169, 8 pages, 2013.

[9] K. Hagiwara, T. Ebihara, N. Urasato, and T. Fujikawa, "Application of ${ }^{129} \mathrm{Xe}$ NMR to structural analysis of $\mathrm{MoS}_{2}$ crystallites on $\mathrm{Mo} / \mathrm{Al}_{2} \mathrm{O}_{3}$ hydrodesulfurization catalyst," Applied Catalysis A: General, vol. 285, no. 1-2, pp. 132-138, 2005.

[10] Y. Feldman, G. L. Frey, M. Homyonfer et al., "Bulk synthesis of inorganic fullerene-like MS2 $(\mathrm{M}=\mathrm{Mo}, \mathrm{W})$ from the respective trioxides and the reaction mechanism," Journal of the American Chemical Society, vol. 118, no. 23, pp. 5362-5367, 1996.

[11] W. K. Hsu, B. H. Chang, Y. Q. Zhu et al., "An alternative route to molybdenum disulfide nanotubes," Journal of the American Chemical Society, vol. 122, no. 41, pp. 10155-10158, 2000.
[12] J. Wang, C. Luo, T. Gao, A. Langrock, A. C. Mignerey, and C. Wang, "An advanced $\mathrm{MoS}_{2}$ / carbon anode for high-performance sodium-ion batteries," Small, vol. 11, pp. 473-481, 2015.

[13] R. Coehoorn, C. Haas, J. Dijkstra, C. J. F. Flipse, R. A. De Groot, and A. Wold, "Electronic structure of $\mathrm{MoSe}_{2}, \mathrm{MoS}_{2}$, and WSe 2 . I. Band-structure calculations and photoelectron spectroscopy," Physical Review B, vol. 35, no. 12, pp. 6195-6202, 1987.

[14] J. A. Glasscock, P. R. F. Barnes, I. C. Plumb, and N. Savvides, "Formation of fractal-like structures driven by carbon nanotubes-based collapsed hollow capsules," The Journal of Physical Chemistry C, vol. 111, pp. 331-337, 2007.

[15] O. Khaselev and J. A. Turner, "A monolithic photovoltaicphotoelectrochemical device for hydrogen production via water splitting," Science, vol. 280, no. 5362, pp. 425-427, 1998.

[16] R. G. Chaudhuri and S. Paria, "Core/shell nanoparticles: classes, properties, synthesis mechanisms, characterization, and applications," Chemical Reviews, vol. 112, no. 4, pp. 2373-2433, 2012.

[17] D. M. Wu, X. D. Zhou, X. Fu, H. Q. Shi, D. B. Wang, and Z. S. $\mathrm{Hu}$, "Synthesis and characterization of molybdenum disulfide micro-sized solid spheres," Journal of Materials Science, vol. 41, no. 17, pp. 5682-5686, 2006.

[18] Z. Wu, D. Wang, and A. Sun, "Surfactant-assisted fabrication of $\mathrm{MoS}_{2}$ nanospheres," Journal of Materials Science, vol. 45, no. 1, pp. 182-187, 2010.

[19] S.-K. Park, S.-H. Yu, S. Woo et al., "A facile and green strategy for the synthesis of $\mathrm{MoS}_{2}$ nanospheres with excellent Li-ion storage properties," CrystEngComm, vol. 14, no. 24, pp. 8323-8325, 2012.

[20] J. Li, P. Wu, Y. Ye et al., "Electronic structure of $\mathrm{MoSe}_{2}, \mathrm{MoS}_{2}$, and $\mathrm{WSe}_{2}$. I. Band-structure calculations and photoelectron spectroscopy," CrystEngComm, vol. 16, no. 4, pp. 517-521, 2014.

[21] G. Paglia, C. E. Buckley, A. L. Rohl et al., "Boehmite derived $\gamma$-alumina system. 1. structural evolution with temperature, with the identification and structural determination of a new transition phase, $\gamma^{\prime}$-alumina," Chemistry of Materials, vol. 16, no. 2, pp. 220-236, 2004.

[22] M. Trueba and S. P. Trasatti, " $\gamma$-alumina as a support for catalysts: a review of fundamental aspects," European Journal of Inorganic Chemistry, vol. 2005, no. 17, pp. 3393-3403, 2005.

[23] F. Lan, Z. Lai, R. Yan et al., "Epitaxial growth of single-crystalline monolayer $\mathrm{MoS}_{2}$ by two-step method," ECS Solid State Letters, vol. 4, pp. 19-21, 2015.

[24] R. Coehoorn, C. Haas, and R. A. de Groot, "Electronic structure of $\mathrm{MoSe}_{2}, \mathrm{MoS}_{2}$, and $\mathrm{WSe}_{2}$. II. The nature of the optical band gaps," Physical Review B: Condensed Matter and Materials Physics, vol. 35, no. 12, pp. 6203-6206, 1987.

[25] K. K. Kam and B. A. Parkinson, "Detailed photocurrent spectroscopy of the semiconducting group VI transition metal dichalcogenides," Journal of Physical Chemistry, vol. 86, no. 4, pp. 463-467, 1982.

[26] T. R. Thurston and J. P. Wilcoxon, "Photooxidation of organic chemicals catalyzed by nanoscale $\mathrm{MoS}_{2}$," The Journal of Physical Chemistry B, vol. 103, no. 1, pp. 11-17, 1999. 

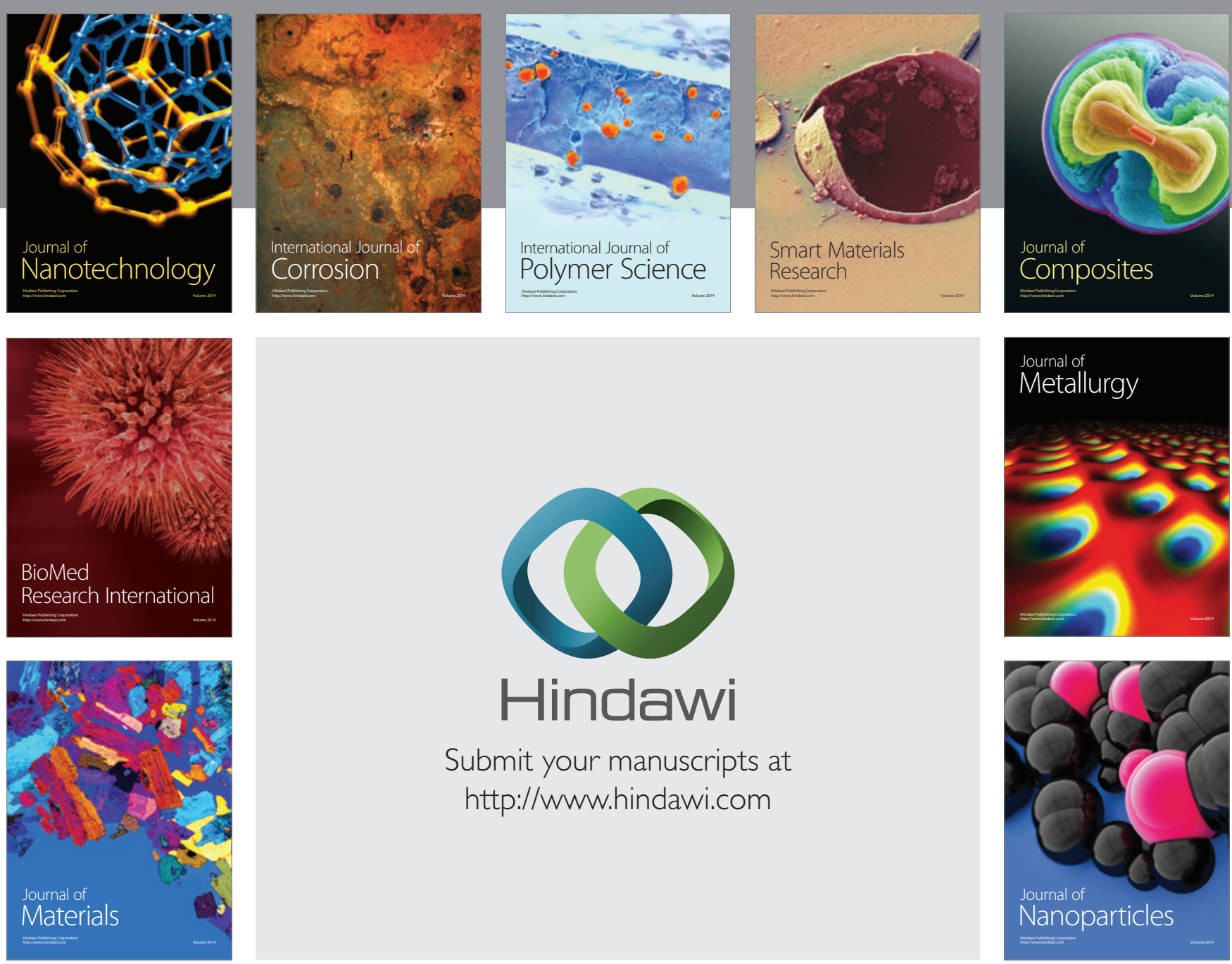

Submit your manuscripts at http://www.hindawi.com
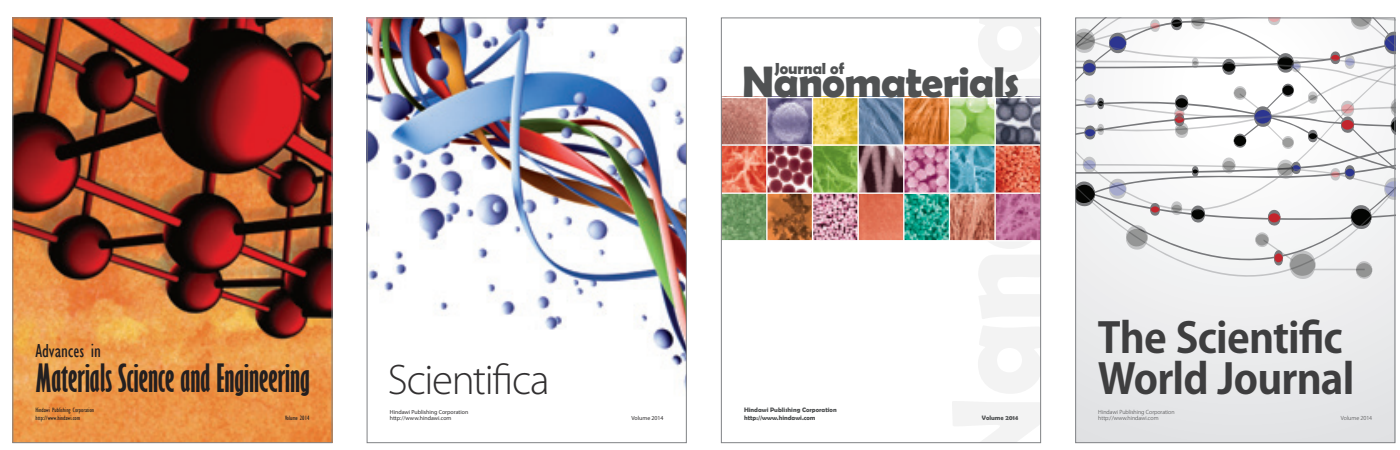

\section{The Scientific World Journal}
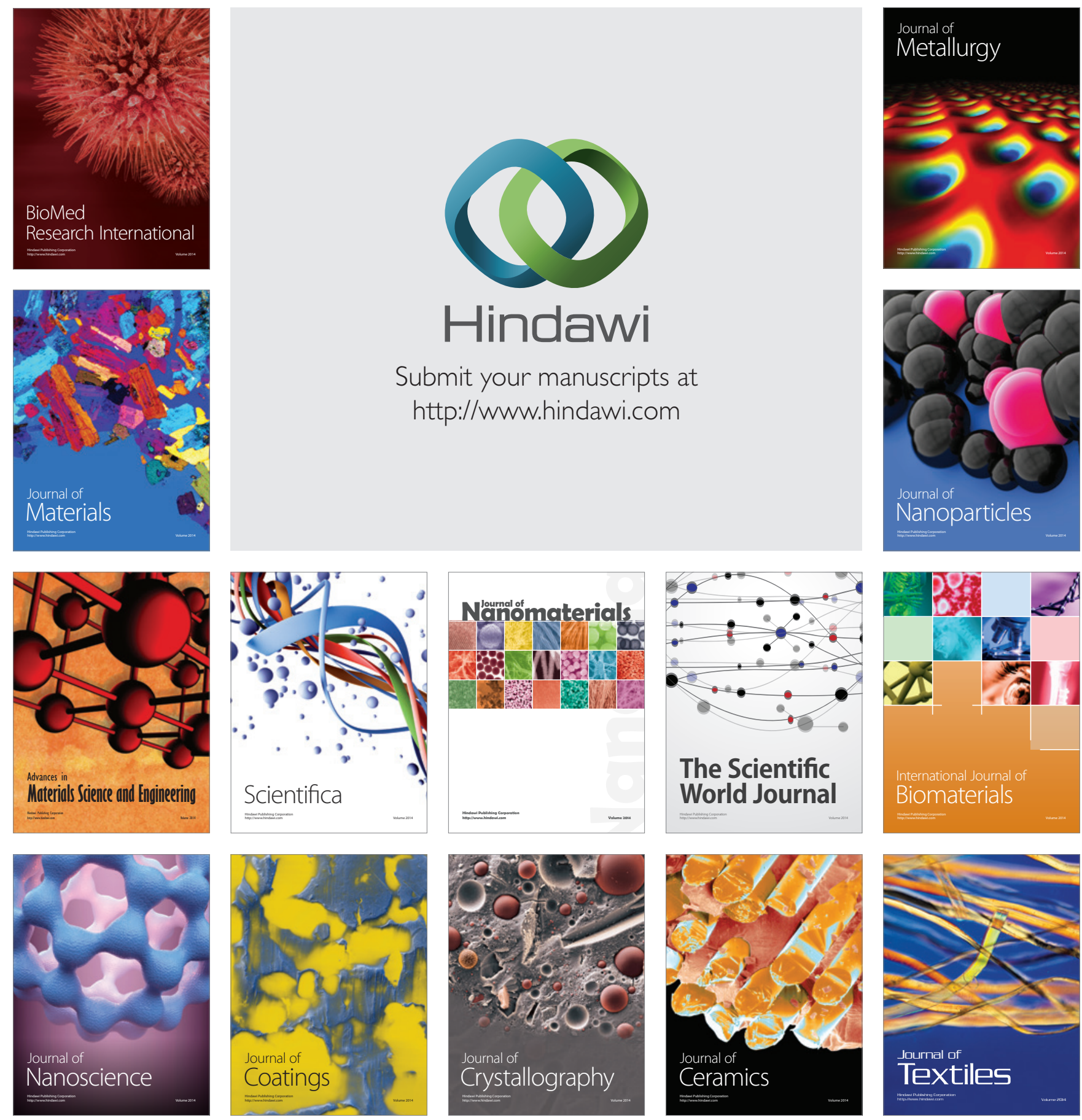